\title{
Analysis of Seroconversion Rate and Factors Associated with Toxoplasmosis in a Rural Area of an Extra-Amazonian Region in Brazil: A Cohort Study
}

\author{
Julyana C. Buery ${ }^{1,3}$, Blima Fux ${ }^{1}$, Ricardo W.A. Vitor ${ }^{2}$, Flávia Sartori ${ }^{1}$ and Crispim Cerutti Junior ${ }^{3, *}$ \\ ${ }^{I}$ Department of Pathology, Federal University of Espírito Santo, Vitória, ES \\ ${ }^{2}$ Department of Parasitology, Federal University of Minas Gerais, Belo Horizonte, MG \\ ${ }^{3}$ Tropical Medicine Unit, Federal University of Espírito Santo, Vitória, ES
}

\begin{abstract}
Background: Toxoplasmosis is caused by the intracellular protozoan Toxoplasma gondii, which has a worldwide distribution. Here, in the first study of asymptomatic infection by this protozoan in the state of Espírito Santo, Brazil, we present an analysis of the prevalence and annual incidence of asymptomatic cases of toxoplasmosis in a rural area of this state.

Methods: Plasma samples from 79 individuals who had responded to questionnaires were analyzed by IgG ELISA, and positive cases were subjected to an IgG avidity test. Follow-up lasted one year and consisted of quarterly visits.

Results: Of the 79 individuals assessed, $67.1 \%$ were positive for IgG anti-Toxoplasma gondii, and the incidence was 6.2 per 100 person-years of observation. No statistically significant association was found between toxoplasmosis and contact with cats or between toxoplasmosis and consumption of pork, mutton or lamb, even if these were undercooked or raw. According to the multivariate analysis, the only risk factor related to infection appears to be increasing age ( $\mathrm{OR}=1.086)$. Confirming the data in the literature, the statistical analysis showed that with every additional year of age the risk of contracting toxoplasmosis increase by $8.6 \%$.

Conclusion: The inhabitants of rural communities in the mountainous region of Espírito Santo are very exposed to Toxoplasma gondii and know very little about the disease, making them vulnerable to exposure.
\end{abstract}

Keywords: Brazil, cohort study, epidemiology, risk factors, rural population, toxoplasmosis.

\section{INTRODUCTION}

Toxoplasmosis is caused by the intracellular protozoan Toxoplasma gondii, which has a worldwide distribution. Morphologically, the protozoan has three evolutionary forms: oocysts, bradyzoites and tachyzoites. For each potentially infectious evolutionary form, the sources of infection vary. In the case of oocysts, infection may be the result of direct contact with cat feces on the ground or ingestion of water, fruit or vegetables contaminated with T. gondii. The disease can also be transmitted to humans by the consumption of raw or undercooked ovine, swine or caprine meat containing tissue cysts [1]. Geoclimatic, social, occupational and nutritional factors, as well as the area where individuals live (i.e., urban or rural), cause the prevalence rate to vary significantly around the world. In the USA the prevalence of infection is relatively low compared with South American countries. Brazil stands out among the

*Address correspondence to this author at the Espírito Santo Federal University. Av. Marechal Campos, 1468 - Vitória-ES - Brazil. CEP: 29.040-090; Tel: 55-27-3335-7225; Fax: 55-27-3335-7200;

E-mail: fil.cris@terra.com.br latter because of its high prevalence, which can be as much as $80 \%$ in some regions [2-4]. In the state of Espírito Santo, two studies of the prevalence in humans report different frequencies. In the municipality of Venda Nova do Imigrante, a prevalence of $11.27 \%$ was found for ocular toxoplasmosis based on the findings of fundoscopy [5]. In the capital of the state, Vitória, a study of pregnant women revealed a prevalence of $73.5 \%$ among women seen in the public health network. This figure was associated with the purchase of meat in street markets. Having attended school for more than four years appeared to be a protective factor for the pregnant women assessed [6]. There is little data on the frequency of $T$. gondii infection among asymptomatic individuals in the state as studies carried out to date have used specific cohorts that are not representative of the whole state.

The present study was conducted in an area that is endemic for malaria. Various suspected cases of this disease were in fact diagnosed as toxoplasmosis at the time of a study by Cerutti et al. (2007) [7]. Both these morbid conditions (malaria and toxoplasmosis) are potentially preventable and require the adoption of public health 
measures. While malaria is the focus of considerable concern because of its unusual transmission mechanism in parts of the Atlantic Forest, toxoplasmosis, as the main differential diagnosis, also needs to be fully characterized from an epidemiological perspective. Here, we analyzed individual and environmental risk factors and their association with anti-Toxoplasma gondii $\mathrm{IgG}$ and estimated the seroconversion rate during almost one year of follow-up. The challenges associated with preventing primary toxoplasmosis in tropical rural areas are discussed.

\section{MATERIALS AND METHODOLOGY}

\section{Study Area}

The study was carried out in a rural area of the municipality of Santa Teresa, approximately $80 \mathrm{~km}$ from Vitória, the capital of Espírito Santo. Officially founded in 1891 when Italian immigrants settled and established villages, the city is still greatly influenced by this culture, particularly in terms of eating and working habits. Of the fifty-one rural communities in the municipality, Lombardia, Valsugana Velha, Rio Saltinho, São José do Caldeirão, Centenário and Patrimônio were investigated (Fig. 1).

\section{Study Design}

The study population consisted of a cohort of residents who were already being followed up to determine the incidence of malaria. The sample was composed of residents living (permanently or not) within a two-kilometer radius of the first malaria case detected in 2011. Ninety individuals attended the call for interview and blood drawing and were enrolled in the study. Of the 90 individuals initially included, 79 agreed to take part in the follow-up to assess toxoplasmosis seroconversion. After the details of the study had been explained to them, participants were asked to sign an informed consent form. Questionnaires were then applied covering the following topics: place of birth; work and leisure activities; how long the individual had lived in the area: and where he or she had lived previously. Questions also covered the presence or otherwise of domestic animals (particularly felids); eating habits; types of work and leisure activities; signs and symptoms suggestive of toxoplasmosis; and when these occurred. New enrollments were not allowed after the initial sampling. Participants were followed up quarterly from March to December 2011.

\section{Laboratory Analysis}

Five milliliters of whole peripheral blood were collected from each individual to test for IgG against $T$. gondii using ELISA. Positive samples then underwent IgG avidity tests to detect seroconversion. Every three months new blood samples were collected and the data on the questionnaires were updated. Four visits were made to each participant, irrespective of whether or not the individual had

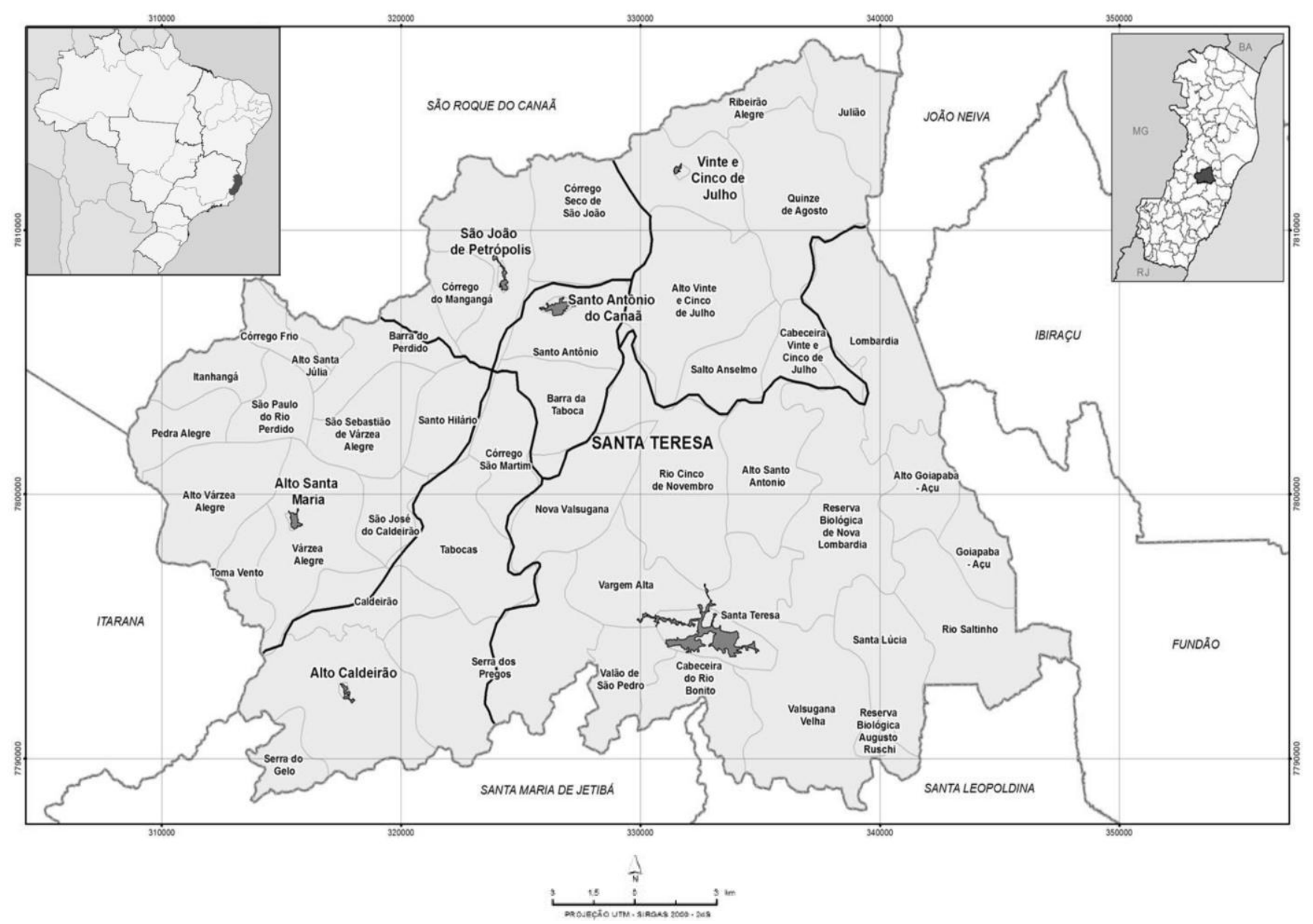

Fig. (1). Map of the administrative limits of Santa Teresa. 
seroconverted. Individuals who were already positive at the first collection were also assessed and followed up, as they were also being evaluated for malaria and their clinical status needed to be checked. Furthermore, if their serological status were found to be constant, this would reinforce the accuracy of the results.

\section{Antigen Preparation}

The protein antigens were obtained from tachyzoites in peritoneal exudate of mice infected with $T$. gondii $(\mathrm{RH}$ strain). To collect the exudate, $3 \mathrm{~mL}$ of PBS pH 7.2 was injected into the animal's peritoneal cavity and the fluid was then extracted with the same syringe without massaging the abdomen. The peritoneal liquid obtained in this way was centrifuged in $15 \mathrm{~mL}$ tubes for $20 \mathrm{~s}$ at $9600 \mathrm{~g}$. The supernatant was discarded, and the pellet was washed with PBS $\mathrm{pH} 7.2$, centrifuged for $10 \mathrm{~min}$ at $2000 \mathrm{rpm}$ and used to prepare a suspension with approximately $1 \times 10^{8}$ to $1 \times 10^{9}$ tachyzoites suspended in $1 \mathrm{~mL}$ of PBS pH 7.2 in a $15 \mathrm{~mL}$ tube which were sonicated at $20 \mathrm{~Hz}$ (in an ice bath) from five to seven times for $45 \mathrm{~s}$ with 2 min intervals between procedures (Ultrasonic Homogenizer - 4710; Cole Palmer Instrument Co.). Parasite rupture was observed between a slide and coverslip under a microscope, and the protein concentration was then measured by the Lowry method.

\section{Detection of Anti-T. Gondii IgG by ELISA}

Human IgG antibody concentration was determined by ELISA using a modification of the technique described by Coutelier et al. in 1986 [8]. Flat-bottomed 96-well polyethylene microplates $\left(\right.$ Sarstedt $^{\mathbb{B}}$ ) that had previously been sensitized overnight at $4^{\circ} \mathrm{C}$ with antigens containing $2000 \mu \mathrm{g}$ of protein $/ \mathrm{mL}$ were used. The plates were then washed twice with $0.87 \% \mathrm{NaCl}$ solution containing $0.05 \%$ Tween 20 in distilled water (wash solution) and blocked with $2 \%$ casein for $30 \mathrm{~min}$ at $37^{\circ} \mathrm{C}$, after which they were washed four times in the wash solution. The plasmas were diluted in a PBS-Tween $200.05 \%$ solution containing casein $0.25 \%$ to a dilution of $1: 100$, and $100 \mu \mathrm{L}$ of the diluted sample were placed in each well in duplicate. Following this, $100 \mu \mathrm{L}$ of peroxidase-labeled anti-human $\operatorname{IgG}$ conjugate were added to each well. The plates were incubated again at $37^{\circ} \mathrm{C}$ for $45 \mathrm{~min}$ and washed four times with wash solution. A $100 \mu \mathrm{L}$ volume of the substrate o-phenylediamine dihydrochloride (OPD) was then added to each well. After incubation for $20 \mathrm{~min}$ at $37^{\circ} \mathrm{C}$, the reaction was stopped by adding $30 \mu \mathrm{L}$ of $4 \mathrm{~N}$ sulfuric acid. Readings were taken at $490 \mathrm{~nm}$ in an ELISA plate reader (Bio-Rad ${ }^{\circledR}$, Model 3550). Six negative sera and two known positive sera previously tested by ELISA were used as controls in duplicate for each plate.

The cut-off was defined as the mean optical density (OD) of the negative control sera plus three standard deviations (SD). The results were expressed as reactivity indices (RI) according to the formula: RI = OD sample / OD cut-off, where RI values $>1.0$ were considered positive and sera with RI between 0.95 and 1.05 were tested again. During the quarterly follow-up of participants, individuals who failed or refused to attend the first blood collection ("no record") and were positive on all the other occasions were considered positive for all the quarterly blood collections. The validity of this assumption was reinforced by the absence of lowavidity results for these samples.

\section{Assessment of IgG Avidity by ELISA}

Adsorption of the antigen to the plate, dilution of the sera and addition of the samples to the wells in duplicate were carried out as described above. For this test, however, each well was incubated for an additional $10 \mathrm{~min}$ at $37^{\circ} \mathrm{C}$ with $100 \mu \mathrm{L}$ of a neutral chaotropic solution of $6 \mathrm{M}$ urea containing $0.02 \mathrm{M}$ PBS-Tween $20 \mathrm{pH} 7.2$. The peroxidaselabeled anti-human $\operatorname{IgG}$ conjugate was used in the same manner as for the IgG test and the reaction was revealed with OPD. The avidity index was calculated as the percentage of ELISA antibody titer retained after exposure to the chaotropic agent compared with the first reaction (IgG ELISA); samples for which this figure was $>50 \%$ were considered to have a high avidity [9]. To minimize the time required and use the same control for both assays, the two tests described above (ELISA to detect IgG and the IgG avidity test) were performed on the same plate.

\section{Data Analysis}

Only the laboratory results from the first blood collection were used to calculate the prevalence of anti- $T$. gondii IgG antibodies in the cohort studied. This was done by calculating a percentage from the gross number of seropositive individuals. The incidence was calculated using the seroconversion rate of the participants over time. The seroconversion rate was calculated with the number of person-years in the denominator normalized to base 100 [10], as the follow-up of the participants lasted one year and consisted of four visits.

Categorical variables were expressed as absolute and relative frequencies. The distribution of continuous quantitative variables was evaluated by determining the central tendency and variability, i.e., the mean and standard deviation if the data had a Gaussian distribution or the median and (interquartile range) IR if the data did not fit this distribution. The chi-square test was used to compare categorical variables except for results lower than five expected for the null hypothesis, when Fisher's exact test was used. In the case of the exposure variable expressed as a continuous quantitative response, the comparison was made with the Mann-Whitney test, as the outcome was dichotomous and the distribution did not fit the Gaussian model. Logistic regression was used to detect the presence of possible confounding variables. Variables were included in the model according to the "enter" method. The criterion was a $p$ value $<0.1$ in the bivariate analysis model. Goodness of fit was tested with the Hosmer-Lemeshow test. Once the odds ratio (OR) had been calculated, a confidence interval of $95 \%$ was estimated.

\section{Study Variables}

The dependent variable was the presence of antiT. gondii $\operatorname{IgG}$ antibodies identified by ELISA in the individuals making up the study population. Because the incidence was low, the association of the different exposures with the probability of being infected at any given moment 
was evaluated, as the seropositive status does not change over time. The independent variables were classified into sociodemographic variables (place of residence, gender, age and occupation) and behavioral characteristics related to the infection (knowledge of toxoplasmosis, presence of pets at the time of the study, places where animals defecate, contact with animals, involvement with activities connected with soil and sand, consumption of raw or undercooked meat and consumption of game). The presence of any of these factors was recorded either in the initial interview or during the follow-up visits when the information was updated. The database was analyzed with SPSS version 21 (SPSS Inc.).

\section{Ethical Considerations}

The study protocol was approved by the Committee for Ethics in Research at the Center for Health Sciences, Federal University of Espírito Santo, Brazil (050/2011). Voluntary informed-consent forms were signed by all the participants or their legally authorized representatives.

\section{RESULTS}

\section{Data Collected in Questionnaires (Table 1)}

Out of a total of 79 individuals, 75 participated in the first visit, 71 in the second, 74 in the third and 73 in the fourth. Forty-two members of the study population $(53.1 \%)$ were male, and there were no pregnant women. Median age was 43.5 years (IR: 16.5 to 58.5 ). The age distribution for the cohort is shown in Fig. (2). Only three individuals (3.85\%) had prior knowledge of toxoplasmosis; these were the only participants who were able to state whether there were any cases of toxoplasmosis in their families. Forty-nine individuals $(62.0 \%)$ reported that their work involved agricultural activities, and only $15(19.0 \%)$ reported that they were not involved in leisure activities in which they came into direct contact with the rural environment, such as fishing or gardening or those requiring contact with woodland. Of the 79 participants, 38 (48.1\%) reported having at least one cat as a pet, and of these, $12(31.57 \%)$ kept a sandbox for the animals to defecate in. The remainder reported that the animals defecated anywhere in the yard. When asked about consumption of game (agoutis, pacas, armadillos etc.), only five individuals (6.41\%) admitted eating this type of meat. Sixty participants $(76.93 \%)$ admitted eating pork or pork sausages at least once a week, and of these, only $18(23.07 \%)$ reported that they frequently or occasionally ate this type of meat raw. In order to look for a relationship between infection by Plasmodium sp. and Toxoplasma gondii, participants were also asked if they had already acquired malaria. In all, $9(11.4 \%)$ reported that they had acquired this disease in the past.

\section{ELISA and IgG Avidity test}

The results of ELISA tests on blood samples collected during the first visit or on samples that were positive on all the other visits revealed that 53 individuals had positive serology for $T$. gondii. The prevalence of toxoplasmosis was therefore $67.1 \%$ (53 out of 79 ; CI $95 \%=56.7 \%-77.5 \%$ ) in the rural area of the municipality. Initially, none of the participants were diagnosed as having had an infection recently based on IgG avidity tests. However, on subsequent visits both tests identified new cases (including cases that were positive in the avidity test). Based on these data, the seroconversion rate of the cohort during the study period was calculated. Of the 79 individuals who took part in the study in 2011,75 presented for the first blood collection. Of these, $26(32.9 \%)$ had been negative for anti- $T$. gondii antibodies in the first plasma sample collected. One participant had seroconverted at the third collection and another two at the fourth, indicating that they had been exposed to the parasite

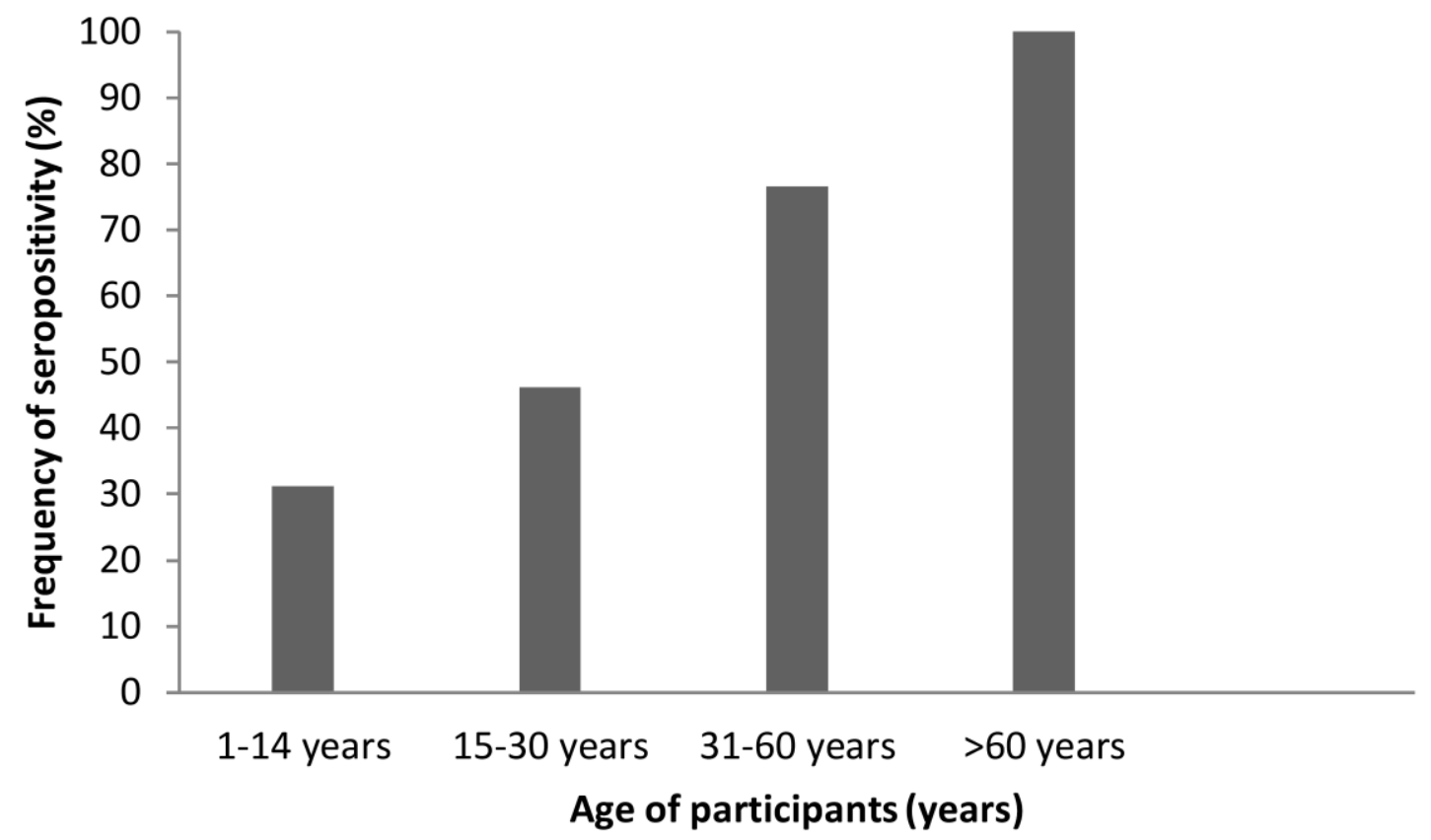

Fig. (2). Seroprevalence of toxoplasmosis by age group in the cohort of Santa Teresa, ES, 2011. 
Table 1. Behavioral characteristics statistically associated with Toxoplasma gondii infection in rural Santa Teresa, ES.

\begin{tabular}{|c|c|c|c|}
\hline Variables & \multicolumn{2}{|c|}{ ELISA } & P Value \\
\hline Male & $25(49.0 \%)$ & $11(56.0 \%)$ & \multirow[t]{2}{*}{0.567} \\
\hline Female & $26(51.0 \%)$ & $11(44.4 \%)$ & \\
\hline $1-14$ years & $5(31.25 \%)$ & $11(68.5 \%)$ & \\
\hline $15-30$ years & $6(46.15 \%)$ & $7(53.85 \%)$ & \\
\hline $31-60$ years & $23(76.6 \%)$ & $7(23.4 \%)$ & \\
\hline$>60$ years & $17(100 \%)$ & $0(0,0 \%)$ & \\
\hline No & $43(84.3 \%)$ & $24(96.0 \%)$ & $0.257^{*}$ \\
\hline \multicolumn{3}{|c|}{ Knowing about having or not having toxoplasmosis } & \multirow{3}{*}{$1.000^{*}$} \\
\hline Yes & $2(3.9 \%)$ & $1(4.0 \%)$ & \\
\hline No & $49(96.1 \%)$ & $24(96.0 \%)$ & \\
\hline \multicolumn{3}{|c|}{$\begin{array}{l}\text { Knowing whether there was a previous episode of symptomatic or } \\
\text { congenital toxoplasmosis in the family }\end{array}$} & \multirow{3}{*}{$0.250^{*}$} \\
\hline Yes & $1(2.0 \%)$ & $2(8.0 \%)$ & \\
\hline No & $50(98.0 \%)$ & $23(92.0 \%)$ & \\
\hline No & $9(17.6 \%)$ & $7(28.0 \%)$ & \multirow{4}{*}{$0.773^{* *}$} \\
\hline Yes, with cats & $2(3.9 \%)$ & $1(4.0 \%)$ & \\
\hline Yes, with dogs & $13(25.5 \%)$ & $5(20.0 \%)$ & \\
\hline Yes, with cats and dogs & $27(52.9 \%)$ & $12(48.0 \%)$ & \\
\hline \multicolumn{3}{|l|}{ Contact with dogs } & \multirow{3}{*}{0.324} \\
\hline Yes & $40(78.4 \%)$ & $17(68.0 \%)$ & \\
\hline No & $11(21.6 \%)$ & $8(32.0 \%)$ & \\
\hline \multicolumn{3}{|l|}{ Contact with cats } & \multirow{3}{*}{0.689} \\
\hline Yes & $29(56.9 \%)$ & $13(52.0 \%)$ & \\
\hline No & $22(43.1 \%)$ & $12(48.0 \%)$ & \\
\hline \multicolumn{3}{|l|}{ Animals have a specific place to defecate } & \multirow{3}{*}{-} \\
\hline Yes & $12(30.0 \%)$ & $0(0.0 \%)$ & \\
\hline No & $28(70.0 \%)$ & $16(100.0 \%)$ & \\
\hline
\end{tabular}


Table 1. Contd.....

\begin{tabular}{|c|c|c|c|}
\hline Variables & \multicolumn{2}{|c|}{ ELISA } & P Value \\
\hline Yes & $4(9.3 \%)$ & $7(28.0 \%)$ & \multirow[t]{2}{*}{$0.084 *$} \\
\hline No & $39(90.7 \%)$ & $18(72.0 \%)$ & \\
\hline Yes & $7(16.3 \%)$ & $4(16.0 \%)$ & \multirow[t]{2}{*}{$1.000^{*}$} \\
\hline No & $36(83.7 \%)$ & $21(84.0 \%)$ & \\
\hline \multicolumn{3}{|c|}{ Leisure activities involving other rural environments } & 0.809 \\
\hline Yes & $10(23.3 \%)$ & $10(40.0 \%)$ & \multirow[t]{2}{*}{0.144} \\
\hline No & $33(76.7 \%)$ & $15(60.0 \%)$ & \\
\hline \multicolumn{3}{|c|}{ Leisure activities involving direct contact with the soil } & \multirow{3}{*}{0.286} \\
\hline Yes & $15(34.9 \%)$ & $12(48.0 \%)$ & \\
\hline No & $28(65.1 \%)$ & $13(52.0 \%)$ & \\
\hline \multicolumn{3}{|c|}{ No contact with the rural environment during leisure activities } & \multirow[b]{2}{*}{0.741} \\
\hline Yes & $11(23.4 \%)$ & $5(20.0 \%)$ & \\
\hline \multicolumn{3}{|l|}{ Consumption of game at present } & \multirow{3}{*}{$1.000^{*}$} \\
\hline Yes & $5(9.8 \%)$ & $2(8.0 \%)$ & \\
\hline No & $46(90.2 \%)$ & $23(92.0 \%)$ & \\
\hline \multicolumn{3}{|l|}{ Consumption of game in the past } & \multirow{4}{*}{$0.277 * *$} \\
\hline No & $43(84.3 \%)$ & $23(92.0 \%)$ & \\
\hline Yes, on average 2 years ago & $5(9.8 \%)$ & $2(8.0 \%)$ & \\
\hline Yes, more than 10 years ago & $3(5.9 \%)$ & $0(0.0 \%)$ & \\
\hline \multicolumn{3}{|c|}{$\begin{array}{l}\text { Frequency with which pork, mutton or lamb (including sausage) is } \\
\text { consumed }\end{array}$} & \multirow{6}{*}{$0.470^{* *}$} \\
\hline Never & $9(17.6 \%)$ & $8(32.0 \%)$ & \\
\hline Every day & $1(2.0 \%)$ & $0(0.0 \%)$ & \\
\hline Several times a week & $2(3.9 \%)$ & $2(8.0 \%)$ & \\
\hline Once a week & $11(21.6 \%)$ & $5(20.0 \%)$ & \\
\hline From time to time & $28(54.9 \%)$ & $10(40.0 \%)$ & \\
\hline
\end{tabular}


Table 1. Contd.....

\begin{tabular}{|l|c|c|}
\hline \multicolumn{1}{|c|}{ Variables } & \multicolumn{2}{|c|}{ PLISA } \\
\cline { 2 - 3 } & Positive & Negative \\
\hline \hline $\begin{array}{l}\text { Frequency with which raw pork, mutton or lamb (including sausages) } \\
\text { is consumed }\end{array}$ & & $21(84.0 \%)$ \\
\hline Never & $37(72.5 \%)$ & $2(8.0 \%)$ \\
\hline Rarely & $4(7.8 \%)$ & $2(8.0 \%)$ \\
\hline Occasionally & $10(19.6 \%)$ & $100.00 \%$ \\
\hline Total & $100.00 \%$ & - \\
\hline$*$ Fisher exact test. & & \\
\hline$* *$ Maximum likelihood. & & \\
\hline
\end{tabular}

during the year. The first individual to seroconvert was female, and the other two male. The woman was 26 and the one male whose age was recorded on the questionnaire was 72 years old. Of these three, the two who answered all the questions did not work in activities connected with the rural environment, their leisure activities involved contact with the land and they stated that they did not eat raw meat or sausages. The seroconversion rate was therefore estimated at 6.2 per 100 person-years of observation (CI 95\% $1.3-18.2$ per 100 people-years). In the IgG avidity test, two of these samples showed a functional affinity of less than $50 \%$, indicating the low avidity of these antibodies for the antigen tested. The other serum sample showed a high avidity in this test $(>50 \%)$.

\section{Seropositivity and Associated Variables}

The bivariate analysis showed that the median age of infected individuals was 52 years (IR: 32 to 65). Comparison of the age distributions for positive and negative individuals using the Mann-Whitney test showed that age was statistically associated with seroconversion (Fig. 2). There was no statistically significant association between gender and contracting the infection $(p=0.567)$. The associations between the various behavioral characteristics studied and seroprevalence in the study sample were investigated. The characteristics that satisfied the criteria for inclusion in the multivariate analysis model $(p<0.2)$ were age, type of work activities, leisure activities involving woodland and leisure activities involving direct contact with animals. In the multivariate analysis of these factors the only positive association was between seropositivity and age, with an adjusted OR of 1.086 (CI 95\% = 1.031-1.145, p-value $=$ 0.002 ) (Table 2), indicating that each additional year of life implies an $8.6 \%$ increase in the risk of infection. The exclusion of age in the multivariable model did not change the association of the other variables with seropositivity (data not shown).

\section{DISCUSSION}

There is still a dearth of literature in Brazil on rural communities and the factors that lead to infection by $T$. gondii in individuals living in these communities, particularly when the infection remains asymptomatic. This study, which was carried out in a rural area of Brazil, found a high prevalence $(67.1 \%)$ of anti-T. gondii antibodies and an annual seroconversion rate of 6.2 per 100 people-years of observation. Seroprevalence was found to increase with age and not to vary with gender. Seropositive individuals were older than individuals who were seronegative (median ages 52 years and 16 years, respectively; Mann-Whitney test: $\mathrm{p}<0.001)$. The number of seropositive children in the present study was approximately one third less than in a study carried out in a rural area of the state of Acre in the Amazon region by Ferreira et al. (2009) [10]. In Santa Teresa most of the population became seropositive later in life, as shown by the seroprevalences: only $46 \%$ of participants were positive by the age of 30 years while by the age of 60 this increased to $76.6 \%$. These figures are different from those reported by Ferreira et al. (2009) [10], who found seroprevalences of $76.8 \%$ and $90 \%$, respectively, for the same age groups. Hence, there was a lower seroconversion rate among young people in this rural area in Espírito Santo, showing that there is an important difference between Amazon and extraAmazonian regions.

The variable age, because of the magnitude of its association, continued to be significant in the multivariate model and proved to be a factor associated with seropositivity. In this population the chance of having a positive IgG ELISA for $T$. gondii increases 1.086 times $(8.6 \%)$ with every additional year of age. This result was expected as, according to various researchers [10-14], an increase in age is directly associated with a greater chance of infection by $T$. gondii, which can be explained by the greater probability of an individual being exposed to different transmission factors. For this reason, many investigators, including Quites et al. (2007) [13], exclude age from multivariate analyses. In the present study, however, exclusion of age did not affect the results for the other variables (results not shown).

Although Quites et al. (2007) [13] reported different results in their study, in which they found a prevalence of $32.57 \%$, various behavioral characteristics and the seroprevalence rate in our study corroborate the findings for 
Table 2. Results of the univariate/bivariate and logistic regression analyses for variables with a statistically significant relationship with toxoplasmosis in rural Santa Teresa, ES, 2011.

\begin{tabular}{|c|c|c|c|c|c|c|}
\hline \multirow{3}{*}{ Variables } & \multicolumn{3}{|c|}{ Results of the univariate/bivariate analysis } & \multicolumn{3}{|c|}{ Results of regression } \\
\hline & \multirow{2}{*}{ p value } & OR & \multirow{2}{*}{$95 \% \mathrm{CI}$} & \multirow{2}{*}{ p value } & OR & \multirow{2}{*}{$95 \% \mathrm{CI}$} \\
\hline & & Crude & & & Adjusted & \\
\hline Do your leisure activities involve direct contact with animals? & 0.144 & & & 0.865 & & \\
\hline Yes & & 0.455 & $0.156-1.323$ & & 0.89 & $0.232-3.413$ \\
\hline No & - & - & - & - & - & - \\
\hline Do your leisure activities involve woodland? & 0.084 & & & 0.12 & & \\
\hline Yes & & 0.264 & $0.068-1.017$ & & 0.28 & $0.056-1.395$ \\
\hline No & - & - & - & - & - & - \\
\hline What type of activity do you do? & 0.042 & & & 0.168 & & \\
\hline Agricultural & & 2.756 & $1.022-7.426$ & & 0.274 & $0.043-1.728$ \\
\hline Non-agricultural & - & - & - & - & - & - \\
\hline Age & 0 & - & - & 0.002 & 1.086 & $1.031-1.145$ \\
\hline
\end{tabular}

* Hosmer-Lemeshow Test $=0.316$ - the model fitted the data well

$\mathrm{p}$ value $<0.05$

another rural Brazilian population (seroprevalence of $65.8 \%$ ) investigated using a design similar to ours [10].

In order to ensure that the data for the cohort in Santa Teresa were typical of rural areas in the highlands of Espírito Santo, a smaller sample of inhabitants of the neighboring municipality of Santa Maria de Jetibá $(28 \mathrm{~km}$ from Santa Teresa) were followed up in parallel. The seroprevalence for this parallel sample using the same laboratory technique was $61.1 \%$ (results not shown).

Different factors related to people's lifestyles are associated with the risk of infection by $T$. gondii, which can be explained by the fact that the infection can be spread in different ways. If one considers that infection by $T$. gondii occurs during different stages of the etiologic agent's lifecycle, i.e., as a result of consumption of food contaminated with oocysts, direct contact with oocysts from cat feces on the ground or by ingesting cysts containing bradyzoites in previously infected animal tissues [14-16], the absence of an association between the high prevalence in the rural area studied and these behavioral factors is curious. With regard to contact with domestic animals (cats and dogs), a relatively large percentage of the study population $(53.2 \%)$ reported contact with the former, although the corresponding figure for dogs was higher (72.2\%). According to Ferreira et al. (2009) [10], the presence of dogs in the home may have been a protective factor in their study, as these animals are able to frighten away cats and wild felids, reducing the risk of contamination of the environment with oocysts. Their data, however, must be interpreted with caution, because in their article having a dog at home was not a protective factor and cluster analysis was not controlled for potential confounding factors. Of those individuals in our study who reported having contact with a pet $(65.8 \%)$, a large percentage (76.92\%) did not know where these animals defecated. This would suggest that the ground or irrigation water may be contaminated with oocysts (in the case of cat feces). As being an agricultural worker was statistically significant $(p=0.042)$ in the bivariate analysis, it can be inferred that direct or indirect contact with the parasite is the result of this type of work rather than contact with the feces of felids. Conditions favorable to oocyst survival and maturation (sporogony) can, in the absence of effective prevention measures, result in the high seroprevalence observed here. In addition, the widespread distribution of the protozoan in this kind of environment and the multiple possibilities for infection would tend to obscure any relationship with specific exposure factors, explaining the lack of any statistically significant association in this study. The contribution made by the transmission of $T$. gondii in water to infection in humans in rural areas of the country has been little studied. However, the consumption of vegetables grown in private vegetable plots $(p=0.0002)$ and the origin of drinking water $(p=0.02)$ were strongly associated $(\mathrm{p}<0.05)$ with seropositivity in rural Amazonia [17]. According to the same study, ingestion of oocysts appears to be the main source of contamination in humans.

With regard to eating habits, $75.9 \%$ of residents admitted eating pork sausage or pork, lamb or mutton at least once a week, although only $20.3 \%$ admitted eating this type of food raw, suggesting that this type of transmission is rare in the region. This finding contradicts data showing an association between this eating habit and a risk of infection with T. gondii $(\mathrm{OR}=2.00, \mathrm{p}=0.01)$ in Erechim, in the interior of the state of Rio Grande do Sul [18]. However, the indigenous tribe Enawenê-Nawê, which has one of the highest 
seroprevalences of $T$. gondii in the country (78.8\%), do not eat any red meat or breed domestic animals, such as chicken, for their own consumption [3], suggesting that the consumption of meat, whether raw or not, does not play a significant role in the transmission of toxoplasmosis in Brazil.

The consumption of game was reported by a small number of individuals $(6.3 \%)$ during the study, but this number increased to $12.7 \%$ when respondents were asked about this type of food in the past (2 to 10 years earlier and more than 10 years earlier). We believe that the information about this issue may be distorted, as hunting animals is forbidden in Brazil [19]. When questioned, many individuals were reluctant to reply to the question "Do you currently eat game?" and although there are not, to our knowledge, any studies quantifying the consumption of this type of meat in Brazil, respondents stated informally that this practice is common in the study area. In light of this, a better approach might have been to include questions about "exotic meats", so that no reference was made to the consumption of forbidden meat. The relationship between prevalence and the location of residents' dwelling places was not analyzed as the cohort was defined during the malaria study using the criterion that participants should live within a $2 \mathrm{~km}$ radius of the first malaria case recorded in the rural area of the municipality. Hence, the small geographic spread of the sample precluded an adequate spatial analysis. During the follow-up there were three cases of seroconversion. Two of these individuals could be assessed at all the blood collections, but the other only at the first and last, when his IgG avidity was already high. Interestingly, at the last collection, low IgG avidity was observed in two other patients who were already seropositive and had had high IgG avidities since the first collection. We believe this finding can be attributed to the fact that in rare cases, low avidity IgG antibodies are still present many years after initial contact with the parasite [20].

The limitations of the present study relate mainly to the sampling process, as it was not probabilistic but based on the relationship between the area where the subjects lived and the occurrence of malaria. Consequently, the figures may not be representative of the real frequency of toxoplasmosis in the population or may not be sufficiently precise to guarantee enough power to detect associations between the several dependent variables and the outcome, a concern made all the greater by the small sample size. Moreover, several characteristics of the subjects were determined based on information provided by the subjects themselves, allowing the introduction of bias related to acceptability and memory. The association of dependent variables with a measure of prevalence also limits the conclusions regarding causality. However, the high prevalence of toxoplasmosis among human populations, the robustness of the analytical methods used, the close agreement between our findings and those of other similar studies and the similarity of the frequencies observed with those recorded in a parallel study in the same area (Santa Maria de Jetibá) make the results of the present study all the more important.

\section{CONCLUSION}

This study has confirmed that the inhabitants of rural communities in the mountainous region of Espírito Santo are highly exposed to $T$. gondii, which is reflected in the high prevalence observed $(67.1 \%)$ and the equally worrying seroconversion rate $(6.2$ per 100 people-years of observation). Our results indicate that of the various factors investigated, only age was associated with contracting T. gondii infection in the community. Although a statistically significant association was not found, the large number of infected individuals in the rural area of the municipality of Santa Teresa may be associated with habits or customs common to residents exposed to factors related to infection investigated in the questionnaire. The widespread distribution of the protozoan in the environment and the fact that the sample investigated had the characteristics of a spatial cluster may have prevented such associations being identified. The residents of the study know extremely little about toxoplasmosis and how the disease is transmitted, making them vulnerable to exposure as a result of practices they consider normal and risk-free. In light of this and the findings of populational studies such as the present study and many others, it is incumbent upon health managers to plan and implement measures related to the provision of information about toxoplasmosis and the control and prevention of the disease, as well as to provide resources for diagnosing those already infected $(67.1 \%)$ in the rural area of the municipality. The similar findings for Santa Maria de Jetibá confirm the need to introduce public-health policies in other mountainous areas of the state of Espírito Santo. The epidemiology of toxoplasmosis is undoubtedly complex, and comprehensive studies addressing socioeconomic, environmental, immunological and genetic issues, among others, have been carried out to elucidate the different mechanisms involved in $T$. gondii transmission and infection. By providing epidemiological information about T. gondii infection, this study lays the basis for the development of strategies to prevent this infection, which is an important public health problem in Brazil and other countries.

\section{AUTHORS' CONTRIBUTIONS}

JCB took part in the study design, performed the immunological assays, took part in the blood collections and wrote the article. BF provided intellectual support and was directly involved in the planning and coordination of the article. RWAV provided the facilities for and supervised the immunoassays at the Toxoplasmosis Laboratory at the Federal University of Minas Gerais (UFMG). FS took part in the blood collections in the field. CCJ took part in the design, preparation and coordination of the study and helped write the article. All the authors read and approved the final manuscript.

\section{CONFLICT OF INTEREST}

The authors confirm that this article content has no conflicts of interest. 


\section{ACKNOWLEDGMENTS}

We would like to thank the team at the UFMG Toxoplasmosis Laboratory, especially Rosálida Lopes. We are also grateful to Fabiano Oliveira for her vital support with the statistical analysis and to the Epidemiological Surveillance Unit at Santa Teresa City Hall, Vanessa Foeger in Santa Maria de Jetibá and the Espírito Santo State Department of Health (SESA). This study was partially funded by the State of Espírito Santo Research Foundation (FAPES).

\section{REFERENCES}

[1] Tenter AM, Heckeroth AR, Weiss LM. Toxoplasma gondii: from animals to humans. Int J Parasitol 2000; 30: 1217-58.

[2] Camargo ME. Toxoplasmosis. In: Diagnóstico laboratorial da principais doenças infecciosas e auto-imunes. Ferreira AW, Avila SLM, Eds. Brazil: Guanabara Koogan 2001; pp. 165-74.

[3] Sobral CA, Amendoeira MR, Teva A, et al. Seroprevalence of infection with Toxoplasma gondii in indigenous Brazilian populations. Am J Trop Med Hyg 2005; 72: 37-41.

[4] Pappas G, Roussos N, Falagas ME, et al. Toxoplasmosis snapshots: Global status of Toxoplasma gondii seroprevalence and implications for pregnancy and congenital toxoplasmosis. Int $\mathrm{J}$ Parasitol 2009; 39: 1385-94.

[5] Abreu MT. Toxoplasmose ocular em venda nova do imigrante, ES, Brasil. Arq Bras Ophthalmol 1998; 61: 540-5.

[6] Areal KR, Miranda AE. Estudo de Soroprevalência de Toxoplasmose em gestantes atendidas na rede Municipal de Saúde de Vitória, ES. NewsLab 2008; 87.

[7] Cerutti C Jr, Boulos M, Coutinho AF, et al. Epidemiologic aspects of the malaria transmission cycle in an area of very low incidence in Brazil. Malar J 2007; 6: 1-12.
[8] Coutelier, JP, Van Roost E, Lambotte P, et al. The murine antibody response to lactate dehydrogenase-elevating virus. J Gen Virol 1986; 67: 1099-108.

[9] Lappalainen M, Hedman K. Serodiagnosis of toxoplasmosis. The impact of measurement of IgG avidity. Ann Ist Super Sanita 2004; 40: $81-8$.

[10] Ferreira MU, Hiramoto RM, Aureliano DP, et al. A communitybased survey of human toxoplasmosis in rural amazonia: seroprevalence, seroconversion rate, and associated risk factors. Am J Trop Med Hyg 2009; 81: 171-6.

[11] Daguer H. Ocorrência da Infecção por Toxoplasma gondii (Nicolle \& Manceaux, 1909) em bovinos e funcionários de matadouros da microrregião de Pato Branco, Paraná, Brasil. Curitiba: Universidade Federal do Paraná 2003.

[12] Montoya JG, Liesenfeld O. Toxoplasmosis. Lancet 2004; 363: 1965-76.

[13] Quites HFO. Fatores associados à infecção com Toxoplasma gondii em comunidade rural do Vale do Jequitinhonha, Minas Gerais Belo Horizonte: Universidade Federal de Minas Gerais 2009.

[14] Elsheikha HM. Congenital toxoplasmosis: priorities for further health promotion action. J Roy Inst Public Health 2008; 122: 33553.

[15] Choi WY, Nam HW, Kwak NH, et al. Foodborne outbreaks of human toxoplasmosis. J Infect Dis 1997; 175: 1280-2.

[16] Dubey JP. The History of Toxoplasma gondii - The First 100 Years. J Eukaryot Microbiol 2008; 55: 467-75.

[17] Cavalcante GT, Aguilar DM, Camargo LM, et al. Seroprevalence of Toxoplasma gondii antibodies in humans from rural Western Amazon, Brazil. J Parasitol 2006; 92: 647-9.

[18] Jones JL, Muccioli C, Belfort R Jr, et al. Recently acquired Toxoplasma gondii infection, Brazil. Emerg Infect Dis J 2003; 12: 582-7.

[19] Brasil, Lei $n^{\circ}$ 5.197, de 3 de janeiro de 1967. Dispõe sobre a proteção à fauna e dá outras providências. Available from: http://www.planalto.gov.br/ccivil_03/leis/L5197.htm (Accessed on february 3, 2013)

[20] Kym YT, Werblin TP, Siskind GW, et al. Distribution of antibodybinding affinity. III. Detection of low affinity antibody in the presence of high affinity antibody. J Immunol 1974; 112: 2002-12.

Received: December 31, 2013

Revised: March 18, 2014

Accepted: March 31, 2014

(C) Buery et al; Licensee Bentham Open.

This is an open access article licensed under the terms of the Creative Commons Attribution Non-Commercial License (http://creativecommons.org/licenses/ by-nc/3.0/) which permits unrestricted, non-commercial use, distribution and reproduction in any medium, provided the work is properly cited. 